\title{
Students' Perception about Learning using MOOC
}

\author{
https://doi.org/10.3991/ijet.v14i18.10802 \\ You Huay Woon \\ Universiti Kebangsaan Malaysia, Bangi Selangor, Malaysia \\ hwyou@ukm. edu. my
}

\begin{abstract}
Massive Open Online Course (MOOC) is an open online course that enhances and provides learning opportunities, particularly in tertiary education, using information technologies. In view of this, this study uses personal characteristics such as learning strategies and cognitive appraisal to identify factors that may influence students in embracing MOOC in their learning process. Moreover, perceived usefulness (PU) and perceived ease of use (PEOU) are the factors that are thought to influence the adoption of MOOC. This study was conducted in a university in Selangor, Malaysia among the pre-university students in the 2018/2019 academic year. Among the 87 students who participated in a MOOC as part of an offline course requirements, 66 students have been randomly selected as the respondents. The quantitative analysis indicates that there are significant positive correlations between PU and PEOU and challenges. In other words, the higher the students' intention to participate in MOOC, the higher is their belief that there would be no difficulties in using it, while having more challenge. In addition, the more the students believe that there are no obstacles in using MOOC, the more deep learners they become and less threatened when using MOOC. On the contrary, when they are more threatened using the MOOC, they tend to become more surface learners. This study demonstrates that the platforms and contents of the MOOC have a major influence on the learning strategies and cognitive appraisal of the students. This mandates multiple options for the MOOC platforms to accommodate learning experiences of students.
\end{abstract}

Keywords - Massive open online course, learning strategies, cognitive appraisal

\section{Introduction}

Massive Open Online Course (MOOC) is a web-based online course that attracts various people globally. MOOC is defined as an online learning environment with learning freedom that is open and easily accessible. MOOC creates novel approach in learning and teaching. The platform provides lecturers or more known as facilitators who facilitate the participation of the participants by engaging and interacting with the participants.

Since the first introduction of MOOC, there has been an ongoing discussion about its' significance in learning environment and academic value [1]. [2] - [4], to name a few, stated that MOOC provides quality education while being accessible. However, some researchers relate MOOC to be damaging to higher education, see [5], [6]. On the other hand, MOOC influences the way students learn and facilitate better perfor- 
mance. To examine this, a group of pre-university students were asked to participate in this study to discover the students' perceptions in using MOOC.

Along with technological development, adopting technology in learning environment is necessary for independent learning among students [7; 8]. Hence, understanding the factors that influence the students' intention to adopt new learning technology is essential. The acceptance of technology has been introduced by [9]. There are two major components in the process of accepting technology, i.e. perceived usefulness (PU) and perceived ease of use (PEOU). PU indicates that it will contribute to deep and meaningful learning by adopting certain technology. On the other hand, PEOU believes that the use of new technology will not be difficult.

Learning strategies examine the students' approaches towards their learning process [10]. This paper investigates the deep versus surface learning approaches in using MOOC. Deep learning is accompanied by high-quality learning outcomes, followed by feeling of success in learning experience as deep learners have the greatest interest and intention to integrate one concept with another in comparison with the surface learners who are only learn important facts in the study. Moreover, deep learning strategies encourage greater learning motivation than surface learning strategies. Hence, students who exercise deep learning strategy tend to have better grades, while surface learners are usually with lower grades.

Cognitive appraisal refers to the student's evaluation of circumstances for the person's well-being. It consists of challenges and threats. Challenge-related emotions are joy and excitement, while stress and anxiety are associated with threats. It has been shown that the more challenging the information are, the higher the student' positive intention in using new technology in learning process [11]. Moreover, it has been demonstrated that challenges and threats can motivate performance especially during examination and learning new skills. Hence, it is crucial to include cognitive appraisal as one of the variables in this study.

In recent years, the concept of MOOC has been developing rapidly and being applied among tertiary education in Malaysia. It has been viewed as a combination of technology and innovation to generally provide learning opportunities for anyone with an internet connection. This indirectly encourages the participants to be an independent learner in their learning experience. To the best of author's knowledge, the study on the pre-university students' perception on MOOC has not been conducted. Hence, in this article, students' perception on integrating of MOOC within classroom interaction is investigated. Personal characteristics in using MOOC will be studied in terms of learning strategies and cognitive appraisal with respect to gender. In addition, the acceptance of technology, i.e. PU and PEOU will be used to reveal the attitude and intention of students in employing MOOC.

The remainder of this paper is structured as follows: Section 2 discusses the methodology implemented in this study. In Section 3, results and discussion are elaborated. Some conclusions and recommendations for future research are given in Section 4. 


\section{Methodology}

This study was conducted in one of the universities in Selangor, Malaysia during the first semester of the 2018/2019 academic year, involving pre-university students. In this study, students who took the Statistics course were requested to sign up for Elementary Statistics course on MOOC, a 17 weeks course. Students were encouraged to participate in the forum, answer quizzes in the MOOC with the monitoring from the facilitator. The contents in the MOOC were part of the offline course requirements.

After that, students were asked to fill in a questionnaire consisting of demographic data, MOOC attitude questionnaires, i.e. PU and PEOU, learning strategies and cognitive appraisal. 66 out of 87 students who sign up the MOOC has been selected as the respondents for this study.

Four questionnaires were used to gather the following data: learning strategies, cognitive appraisal and two MOOC attitude questionnaires. All the statements in the questionnaire were rated on a 5-point Likert scale ( $1=$ strongly disagree; $5=$ strongly agree). In addition, the value of Cronbach's Alpha was higher than 0.70 for each questionnaire.

The learning strategies questionnaire consisted of 14 statements, comprising of two factors: deep and surface learning strategies, with seven items for deep learning and seven for surface learning. This questionnaire was previously validated by [12] and [13].

The students' feelings when confronted with new situations were measured using the cognitive appraisal questionnaire. It consisted of 9 statements, with two factors, which were threats and challenges with six and three items, respectively.

The first attitude questionnaire examined MOOC's PU and consisted of three statements. Moreover, the second attitude questionnaire addressed MOOC's PEOU and comprised of three statements and both MOOC attitude questionnaires were based on [14].

\section{$3 \quad$ Results and Discussion}

Of the whole sample, $25(37.88 \%)$ respondents were male and $41(62.12 \%)$ were female. Their average age was 17.97. Means and standard deviations for the study variables (cognitive appraisal, learning strategies and MOOC attitude) are presented in Table 1. It seems that when using MOOC, male students are more threatened than female students. However, there is similar challenges among male and female students. Further, it appears that female students are deeper learners than male students who are more surface learners. In terms of PU, male students adopted MOOC to improve their performance compared to female students. Nevertheless, female students are more willing to believe that there would be no difficulties in using MOOC in learning than male students (the variables were evaluated on a scale of 1 to 5). 
Table 1. Means and standard deviations of threat, challenge, deep and surface learning, PU and PEOU

\begin{tabular}{|l|c|c|c|c|}
\hline \multirow{2}{*}{ Measures } & \multicolumn{2}{|c|}{ Male } & \multicolumn{2}{c|}{ Female } \\
\cline { 2 - 5 } & $\boldsymbol{M}$ & $\boldsymbol{S D}$ & $\boldsymbol{M}$ & .62 \\
\hline Threat & 2.15 & .76 & 1.90 & .73 \\
\hline Challenge & 3.44 & .66 & 3.36 & 1.38 \\
\hline Deep & 3.18 & .52 & 3.42 & .50 \\
\hline Surface & 2.78 & .51 & 2.59 & .77 \\
\hline PU & 3.76 & .49 & 3.65 & .72 \\
\hline PEOU & 3.56 & .72 & 3.77 & \\
\hline
\end{tabular}

In examining the relationship between gender, PU, PEOU, learning strategies and cognitive appraisal, Pearson correlations were computed in Table 2. The significant positive correlations between PU and PEOU indicates that the higher the students believe there are no difficulties in using MOOC, the better they are in adopting it for better academic performance. In addition, there is a significant positive correlation between deep learning and PEOU, demonstrating higher students' belief in using MOOC without any difficulties, leading to them having deep learning using MOOC. Similarly, there is a significant positive correlation between surface learning and threats. This shows that the higher the students being threatened, the more surface learners they are. Significant positive correlation is also revealed between challenge and PU, showing that the more challenges the students face, the higher the level of $\mathrm{PU}$, i.e. high motivation in adopting MOOC for better academic performance. Further, significant negative correlation was found between threats and PEOU. In other words, the less threatened students are, the higher the students are convinced that using the MOOC would not be difficult.

Table 2. Pearson correlations between gender, PU, PEOU, learning strategies, cognitive appraisal

\begin{tabular}{|l|c|c|c|c|c|c|}
\hline \multicolumn{1}{|c|}{ Measures } & Gender & PU & PEOU & Deep & Threat & Surface \\
\hline Gender & & & & & & \\
\hline PU & -.079 & & & & & \\
\hline PEOU & .143 & $.275^{*}$ & & & & \\
\hline Deep & .105 & .148 & $.306^{*}$ & & & \\
\hline Threat & -.176 & -.235 & $-.358^{* *}$ & -.230 & & \\
\hline Surface & -.177 & .080 & -.064 & .086 & $.245^{*}$ & \\
\hline Challenge & -.058 & $.247^{*}$ & .143 & .211 & -.054 & -.199 \\
\hline
\end{tabular}

*. Correlation is significant at the 0.05 level (2-tailed).

$* *$. Correlation is significant at the 0.01 level (2-tailed). $* \mathrm{p}<0.05 ; * * \mathrm{p}<0.01$

This study demonstrates that the two MOOC attitudes, as well as other personal and demographic characteristics predict the likelihood of MOOC adoption. The two MOOC attitudes, i.e. PU and PEOU play an important role in influencing the students' intention to enroll in MOOC. These results indicate that students will use MOOC if they perceive that the MOOC is beneficial and will improve their learning outcomes. In addition, students will use MOOC if they find it to be friendly and sim- 
ple. In view of this, lecturers should present to the students the usefulness and ease of use of the MOOC to encourage the adoption of MOOC in their learning process. However, the study revealed an interesting finding that the higher the students perception of MOOC's PEOU, the deep learners and less threated they are of MOOC. Hence, for those students who are surface learners, the PEOU is an important factor in influencing the decision to participate in MOOC. On a flip side, the more threatened students are, the more surface learners they will be. To address this, lecturers should emphasize the usefulness and ease of use of MOOC by improving MOOC platform to reduce the threat level among students.

\section{Conclusion}

The present study investigated the two MOOC attitudes, personal characteristics which include learning strategies, cognitive appraisal and demographic variables such as gender in their learning process using MOOC. From the results, it shows that female students are more deep learners and less threatened than the male students when adopting the MOOC in their learning process. Moreover, significant positive correlations were found between PU, PEOU and challenges. In other words, the higher the students' intention to enroll MOOC, the higher their belief that there would not present any difficulties and challenges in participating MOOC. Further, significant positive correlations were found between PEOU and deep learning strategy and significant negative correlations were found between PEOU and threats. This indicates that the higher the students perception on the ease of use of MOOC, the more deep learners they are and the less threatened they are in using MOOC. Besides, the more threatened the students are of MOOC, the more surface learners they are. Findings also reveal that students have different individual characteristics when it comes to accepting technology, i.e. when considering adopting technology in their study environment.

Nevertheless, there are some limitations in this study. Firstly, to generalize to a bigger population, further studies are recommended to include a larger number of students who incorporate MOOC in their learning. In addition, as this study primarily involved pre-university students from one of the universities in Selangor, Malaysia, future researchers can conduct a comparative study on students' perception on MOOC among pre-university, undergraduate and postgraduate students in public and private universities.

\section{$5 \quad$ References}

[1] Conole, G. (2013). MOOCs as disruptive technologies: Strategies for enhancing the learner experience and quality of MOOCs. Journal of Distance Education, 39: 1-17. https://doi. org/10.6018/red/50/2

[2] Eamon, C., James, B., Mark, B., \& Laurence, D. (2018). In MOOCs we trust: Learner perceptions of MOOC quality via trust and credibility. International Journal of Emerging Technologies in Learning, 13(6): 214-222. https://doi.org/10.3991/ijet.v13i06.8447 
[3] Zhou, M. (2016). Chinese university students' acceptance of MOOCs: A selfdetermination perspective. Computers \& Education, 92-93: 194-203. https://doi.org/10.101 6/j.compedu.2015.10.012

[4] Zhu, T. (2016). Empirical research on the effectiveness of MOOCs in developing design students on Sino-foreign cooperation university programs. International Journal of Emerging Technologies in Learning, 11(6): 19-27. https://doi.org/10.3991/ijet.v11i06.5304

[5] Mackness, J., Mak, S., \& William, R. (2010). The ideals and reality of participating in MOOC. Proceedings of the 7th International Conference on Networked Learning 2010, 266-274.

[6] Miguel, J., Caballe, S., \& Proeto, J. (2013). Providing information security to MOOC: Towards affecting student authentication. 5th International Conference on Intelligent Networking and Collaborative Systems. https://doi.org/10.1109/incos.2013.52

[7] Fariza, K. (2019). Students' identities and its relationships with their engagement in an online learning community. International Journal of Emerging Technologies in Learning, 14(5): 4-19.

[8] Satria, F. P., Bobby, A. M., \& Reny, N. (2019). Understanding the Generation Z behavior on D-learning: A unified theory of acceptance and use of technology (UTAUT) approach. International Journal of Emerging Technologies in Learning, 14(5): 20-33.

[9] Davis, F. (1989). Perceived usefulness, perceived ease of use, and user acceptance of information technology. MIS Quarterly, 13(3): 319-339. https://doi.org/10.2307/249008

[10] Von Stumm, S., \& Furnham, A. F. (2012). Learning approaches: Associations with typical intellectual engagement, intelligence and the big five. Personality and Individual Differences. Personality and Individual Differences, 53(5): 720-723. https://doi.org/10.101 6/j.paid.2012.05.014

[11] Aharony, N. (2014a). The effect of personal and situational factors on LIS students' and professionals' intentions to use e-books. Library \& Information Science Research, 36(2): 106-113. https://doi.org/10.1016/j.lisr.2014.01.001

[12] Aharony, N. (2009). The influence of LIS students' personality characteristics on their perceptions towards Web 2.0 use. Journal of Librarianship and Information Science, 41(4): 227-241. https://doi.org/10.1177/0961000609345088

[13] Aharony, N. (2014b). Library and information science students' perceptions of mLearning. Journal of Librarianship and Information Science, 46(1): 48-61. https://doi.org/ $10.1177 / 0961000613518819$

[14] Aharony, N., \& Bar-Ilan, J. (2016). Students' perceptions on MOOCs: An exploratory study. Interdisciplinary Journal of e-Skills and Life Long Learning, 12: 145-162. https://doi.org/10.28945/3540

\section{Author}

You Huay Woon is a senior lecturer in the Pusat GENIUS@Pintar Negara, Universiti Kebangsaan Malaysia (UKM). She received her PhD in Applied Statistics in 2015 from the School of Mathematical Sciences, Universiti Sains Malaysia (USM). Her research interest is in Statistical Process Control. She has immense skills in Statistical Analysis and Data Analysis.

Article submitted 2019-05-05. Resubmitted 2019-06-27. Final acceptance 2019-06-28. Final version published as submitted by the authors. 